\title{
Cover Slip
}

National Cancer Institute

\section{Source}

National Cancer Institute. Cover Slip. NCI Thesaurus. Code C126370.

A thin flat piece of transparent material that is placed over a specimen for viewing with a microscope. 